\title{
Emotional Skills - Key Components in the Interpersonal Relationship
}

\author{
Maria João Rosa da Silva \\ mjoaorosa14@hotmail.com \\ Doctoral student in Management
}

Felipa Lopes dos Reis

felipareis@net.sapo.pt

Ph.D. in Management

Received: June 23, 2011 Accepted: July 03, 2011 DOI: 10.5296/jpag.v1i1.737

\begin{abstract}
The object of this study relates to the level of importance of emotional intelligence and emotions in the process of decision making, and how these elements intervene in interpersonal relationships. In this sense, the general goal of this research project is centred in the ability of the human being to understand and manage his emotions, as well as his capacity to conduct those of others, in the interpersonal relationships established in organizations, at both endogenous and exogenous levels.

An extensive revision was carried out, of the literature which contributed to the building of a logical theoretical frame, and which located reflections on the thematic of emotions, emotional intelligence, facial expressions and decision making.

To carry out this research, the methodological procedures used consisted in the development of a descriptive research, a case study, co-relational and transversal; and the method employed was quantitative, based on the use of a questionnaire.

The sampling was, non-probabilistic by convenience, limited to 60 people, having presented the inevitability of the representation of the chosen population, in a way to adequately reflect the needs showed in the study. The generated data were processed by software. From the analyses of the generated data, it was possible to obtain an answer to the question posed by the study, having been shown the need for a stimulus to occur, in order to generate an emotion, and a consequent making of a decision, where the emotional intelligence is a means which should positively intervene, in compliance with the elements retrieved from the
\end{abstract}


analysis of the referred bibliography. The results obtained supported the formulated hypothesis.

The greater part of the respondents showed ease in the contact with other individuals around them, having established stable proximities, and revealing an elevated predisposition to interact, even if that interaction should imply the need for behaviour adjustments. One can infer that from behaviours of this nature only positive relationships can occur, in which case the emotional component of the individuals can be considered balanced, revealing emotional intelligence.

Keywords: Emotional intelligence, Emotions, Decision making.

\section{Introduction}

The modification in organically contemporary societies can't be ignored, and all the resulting provoked much influence on human behavior. These updates originate from new social challenges, and the resulting transformations in behavior, which makes it an indispensable emotional learning, which can enable concerning intra-and interpersonal balance.

In this perspective, people should develop competence, in order to achieve harness the energy of their emotions in a positive motivational aspect, i.e., the human being from the surrounding environment perceives impulses, that in most cases was trigger negative emotions, resulting in inappropriate decision-making, thus creating conflicting interaction. If people make an appropriate emotional learning, of course, the environments and inconstant conflicting tend to decrease, creating an harmonious interaction.

The study of emotional problematic has been a passionate and engaging matter, has arisen several reflexes, which is increasingly pointing to the construction of emotional intelligence as a phenomenon, procedural emotion in human relational interaction, ie, it starts from the ratification of emotions as adaptive process of the person to the environment, the emotional intelligence was perceived and represented as a process of refurbishments of man to human dynamic contexts. It also refers that in recent decades studies were concerning emotional component to the detriment of rational, both at level of individuals and individual / organization, observing that an increasing applied by various organizations, the theories that have been formulated about these matters.

So with this study we intend to answer the question: "How much do the impulses influence the emotions that originate the decision-making concerning interpersonal relationship?".

\section{Theoretical Framework}

The research aimed bibliography tried to locate reflexes on thematic of emotional intelligence, the emotions and decision-making

\subsection{Emotions}

The emotions play a central role in the functioning human psychology, which has been at least taken on by various theoretical, however, not always clear their resolution settings and reaches unanimity, depending on the emphasis given by different theories and specificity of 
components on which they rely, or factors such as the genetically, environmental, relational and cultural.

To the resolution of an emotion, a process simplification neurobiological as Damásio (2003), consists of a range psychological and physics, triggered by a impulse, subjectively experienced and automatics that puts a state response to impulse, ie, the emotions so a natural means of assessing the environment around us and react adaptively.

Goleman (1997: 310) refer: "... emotion as referring to a feeling and reasoning derivate, states psychological and biological, and the range of likely to action. There are hundreds of emotions, including combinations thereof, variations, mutations and shades. "

Pinto (2001: 243) argues: "A thrill a subjective experience that involves the whole person, body and mind triggered by a complex one and involves thinking or impulse organic reasons and personal sensations. It's a response that involves different components, namely an observable reaction, physiological an excitement, a cognitive interpretations and subjective experience. "

Goleman (1997: 50) argues, based on the thoughts of António Damásio, that the emotions either were important with respect to rationality. So in a sense, humans have two brains and two minds, two different types of intelligence: the rational and emotional. When you shake the feeling and thought, the emotional faculty guides our decisions at the time, works by binding to the rational mind, allowing or preventing the own thought. Similarly, mind thinking plays a decision roles in our emotions, in exception of the emotions are out of control and emotional mind dominates.

It seems to be possible frame this study in the context of problematic of emotions, a brief overview of leadership from it shows the high level of importance that emotions allege how exercised. We choose to mention a specific case of a leadership, José Mourinho, which seems to be the perfect image of an effective leadership.

Lourenço (2009: 31) says that, the way that Mourinho uses, the reason to understand their emotions and those of your workgroup, making reasonable decisions in environments intensely emotional, projected as a "master" in heavy task of leading and motivating your group. This designation assigned to, which is based essentially on the set of characteristics that shows, often combining a constant and front communication with team members, with a stable release between reasons (competence and capacity analysis) and emotion (concerning human motivation and personal).

The leadership of Mourinho is in consonance with the reasoning presented by Goleman (2007) on the emotions and the leaders, saying that no leader has the ability to manage emotions of the other elements of the group, if it's not able to manage their own emotions. Mourinho to study the behaviour of their employees and even of their adversary analyzes the emotions so intrinsic, removing learning to control their emotions.

\subsection{Emotional Intelligence}

Goleman (1999: 323) defines Emotional Intelligence "as the ability to recognize our feelings 
and those of others, motivating us and we manage well the emotions in themselves in our relationships."

Goleman (2007: 59) establishes four domains of emotional intelligence and the eighteen associated competences as follows:

\begin{tabular}{|l|l|l|}
\hline & \multirow{2}{*}{ SELF-CONSCIOUSNESS } & $\begin{array}{l}\text { Emotional Self-Awareness } \\
\text { Self-evaluation } \\
\text { Self-reliance }\end{array}$ \\
\cline { 2 - 3 } & & $\begin{array}{l}\text { Emotional self-control } \\
\text { Transparency }\end{array}$ \\
Capacity for Adaptation \\
Output Capacity
\end{tabular}

Goleman (2007: 40) argues that the analysis of emotional intelligence and their competence, described above, there are skills that enable to describe the dynamics of this whole phenomenon, and to provide simultaneous lines of orientation practice to develop the capacity of leadership. He also notes, that the competences of Emotional Intelligence weren't our innate aptitudes, but acquired. Goleman meant that the leadership works best across the emotionally intelligent leaders, and they generate resonance, i.e., are more efficient. Emotional competence seized, based on emotional intelligence, resulting in outstanding performance at work.

Lourenço (2009) by making a league with the emotional component of leadership Mourinho, states that the emotional interface with its powerful group, based on emotions. In the field of emotional intelligence, being a leader what is known as being emotional, which facilitates the knowledge of others, and with their high self-confidence, relying also those around him consequently accrue an empathy which facilitates a complete wavelength. As Lourenço 
(2009), José Mourinho is a leader presenting in a form of leadership the four domains of emotional intelligence sketched.

\subsection{Facial Expressions}

When addressing the issues of emotions and emotional intelligence, it is inevitable to refer to studies conducted by Paul Ekman on facial expressions, which reveal the physiological changes resulting from a particular emotion.

Goleman (1997: 311) talks about the speed of the emotional mind compared to the rational mind, the time interval between the impulse that triggers an emotion in their reaction almost there, i.e., of Mils seconds, while the rational mind makes a deliberate and analytical reflection spending more time. This sense that Goleman refers Ekman experiences and identifying emotions from imperceptive updates of the terms facials. Thus, they get emotional expressions to reveal itself in modifications of the facial muscles few mils seconds after the event that triggers the reaction.

The facial expressions, exhibit emotional, and that obviously emerge immediate impact in that cause, whether in people that are addressed or watched. The individuals use the facial expressions and / or body, in interpersonal relating, in various combinations in order to convey certain meanings and omit others, arising from their emotional interactions.

Thus, the study or the mere observation of facial expressions of people around us, and which tend to be demonstrative of emotions they experience in social contact may be an interesting element to our social performance, since they are an input reference to our emotional manifestations, and consequently to a potential balanced interpersonal relationships.

\subsection{Decision Making}

António Damásio (2000: 185) supports the hypothesis that the experiences acquired throughout life, are classified as pleasant or unpleasant, give rise to a signal of positive or negative nature, through the mechanism of "somatic marker". Subsequently, the process of decision making, the body uses this mechanism to eliminate or select hypotheses, such that only a small set of options is finally examined "rational."

Referring to the theme of decision making, Goleman (1997: 311) argues that the emotional mind unleashes actions faster than the rational mind, because it stimulates the brain, the mechanism of survival. Thus, emotions also work for making decisions, and even a great source of information. When someone's behavior in the awkward, our emotions prompt us and it is therefore important to learn to trust our emotions and feelings, for a decision.

Robbins (2004: 41) when he mentions the problem of emotions, he makes a brief approach to decision making. Thus, he states that traditionally emphasizes decision making rationality, but it will be nonsense to ignore that the emotional state of those who make decisions are unaffected. In the process of decision making is necessary to consider the "heart" and "mind." The process of decision making must integrate the emotions otherwise the analysis would be inaccurate.

As the bibliography, it appears that a balanced emotional level (control of emotions) is a 
positive factor in a decision making thoughtful and well accepted in interpersonal relationships. Conversely, if there is a situation of absence or low emotional balance (not control emotions), certainly affect the decision making and consequently appear stormy interpersonal relationships.

It will then be needed to learn to discover the secrets of emotional intelligence, so that you can wake up these dormant brain capacities eventually used or not, to develop skills and competencies essential in interpersonal relationships and hence in decision making at both personal as occupation.

So, given that decisions are choices, one might consider that a good decision-making is the result of a good choice.

We can indeed conclude that the decision-making is an inevitable consequence of the discovery of a stimulus or impulse that provokes an emotion, and may or may not be influenced by rational component. Emotional intelligence plays an important role in the process of decision making, in that it operates as an equilibrating emotional behavior.

\section{Research Methodology}

In developing a research work is imperative to carry out careful planning, i.e., should be defined directions of work to be developed.

The overall objective of this research project is the study of capabilities that human beings possess in order to understand and manage their emotions as well as conduct of others, interpersonal relationships found in organizations both endogenous and exogenous.

So, given its interest, the subject of study for this research relates to the analysis of the level of importance of emotional intelligence and emotions in decision making, and to what extent are elements involved in interpersonal relationships.

Given the nature of this study, this research project sought to find points of convergence within the available literature, or that it was possible to see, to prove, as the emotions and emotional intelligence consists of several skills, acquire an effective and decisive importance in making decision and consequent social relations found in the environments surrounding the human being. In an attempt to confirm the reflections presented by several authors, the questionnaire was chosen as a tool for analyzing data consisting of phrases that present situations that can analyze the emotional skills of those selected for the sample. Thus, the specific objectives of this work: to understand how to establish an intra-and interpersonal relationship positive, and the extent to which emotional intelligence is a factor, contributing to the dissemination of the concepts inherent in the theme of emotions and emotional behaviors, recognize the type of strategies emotional management of humans and to evaluate the importance levels of emotional intelligence in human behavior.

As the study type to use depends on the problem that we intend to study, according to the research problem and formulated in order to achieve the targets, we chose to conduct a quantitative study with descriptive types of research, case study, correlaccional and transversal. 
The population chosen is embedded in social group medium / high, of both sexes, between a wide age group, ranging between 20 years and 65 years old, with Western cultural concepts, presents a diversity of academic qualifications, performs administrative and managerial positions

The sample is not probabilistic by convenience and it was easy to approach the elements that compose it, allowing successful participatory, was limited to a number of 60 people selected as representative of the population involves a total of 200 people. It was this, the inevitability of the representativeness of the population chosen.

Variables were defined: independent - environmental situation / stimulus; player - emotion; dependent - decision-making.

The hypotheses were obtained in a deductive way, i.e., from the study and analysis of documented information.

H1: There is influence of the stimulus in the emotions that originate decision making in interpersonal relationships; H2: There is no influence of the stimulus in the emotions that originate decision making in interpersonal relationships; H3: Emotional intelligence is a key factor in decision making; H4: Emotional intelligence is not a determining factor in decision making.

Descriptive statistics and graphic expression of the information is much more than simple methods for the results. Thus, we resorted to the computer processing using the programs, SPSS version 17.0 and Microsoft Office Excel 2007.

\section{Investigation Results}

Regarding the age factor, we opted for the clustering of ages at five intervals: up to 25 years: 26 to 35 years, 36 to 45 years: 46 to 55 years, 56 years or older.

As can be seen in Graph 1, the largest number of respondents lies in the range for the age group between 36 and 45 years, which constitutes $33.33 \%$ of the total sample, i.e. 20 respondents.

\section{Graph 1 - Distribution of sample according to Age}

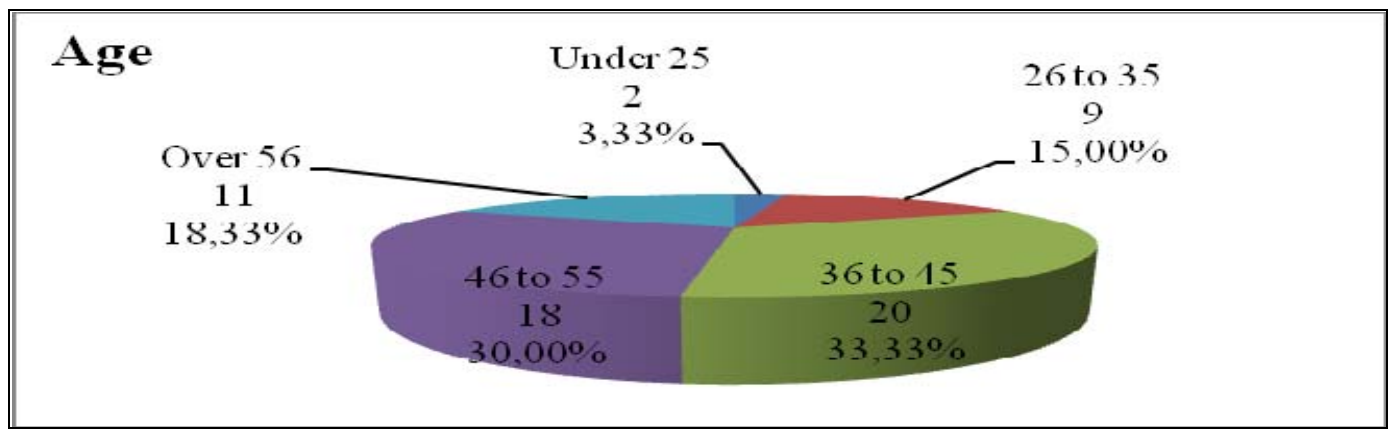

Source: Own (2010)

Regarding the gender factor, we can see from the analysis of Graph 2, a heterogeneity in the 


\section{Macrothink}

distribution of the sample, i.e., there is a prevalence of female gender, with $70 \%$ of the sample, rather than just male found $30 \%$ of the sample reporting . This disparity in outcome exists mainly because the components of the sample selected perform administrative functions, which is historically linked to the female gender.

\section{Graph 2 - Distribution of sample according to Gender}

\section{Gender}

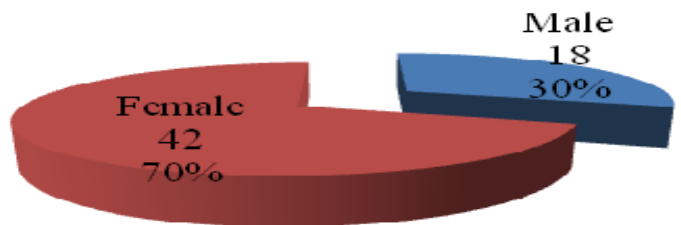

Source: Own (2010)

In Graph 3 shows that there is a certain homogeneity between the number of respondents in the higher technical and administrative role, being respectively 20 and 27, corresponding to the percentages of $33.33 \%$ and $45 \%$, compared to mention that the number of respondents with the task of leadership was 13 , equivalent to $21.67 \%$.

\section{Graph 3 - Distribution of sample according to the Performed Function}

\section{Performed Function}

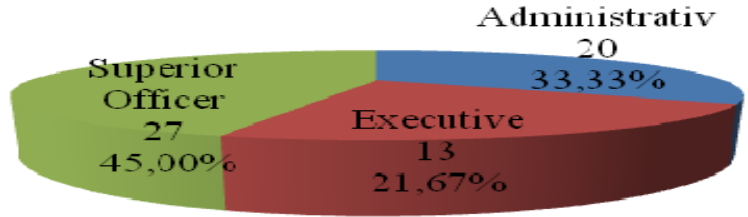

Source: Own (2010)

For the factor time of service, we have chosen to use the aggregation intervals of years: up to 5, from 6 to 10,11 to 15,16 to 20,21 to 25,26 or more years.

In Graph 4 we can see that the range corresponding to 26 or more years of service time obtained the highest value of 21 respondents, representing 35\%, followed with some distance, the ranges of 11 to 15 years and 16 to 20 years, reaching respectively $12 \%$ and 20 respondents with 11 respondents with $18.33 \%$.

This suggests that the selected sample has a high professional experience, thus providing better analysis of the emotional component.

These results are justified, taking into account the data reported in Chart 1 as the average age of the sample that there was between 46 and 55 years old, is perfectly plausible that develop their roles to about 26 years. 


\section{Macrothink}

Graph 4 - Percentage distribution of the sample according to the Service Years

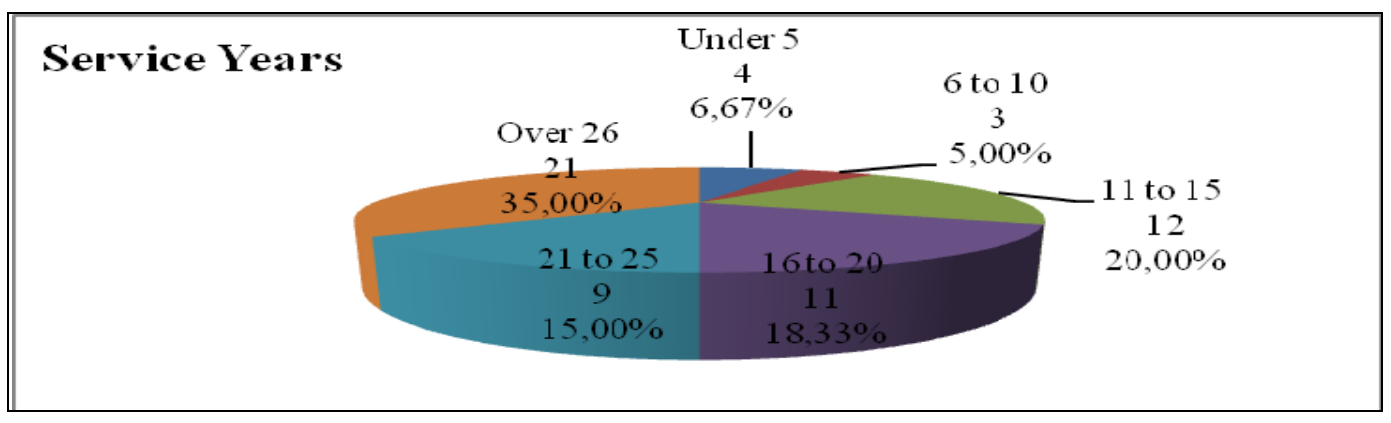

Source: Own (2010)

Graph 5 shows the sample distribution according to educational attainment, which mostly features 36 individuals with undergraduate accounting for $60 \%$

\section{Graph 5 - Distribution of sample according Academic Qualifications}

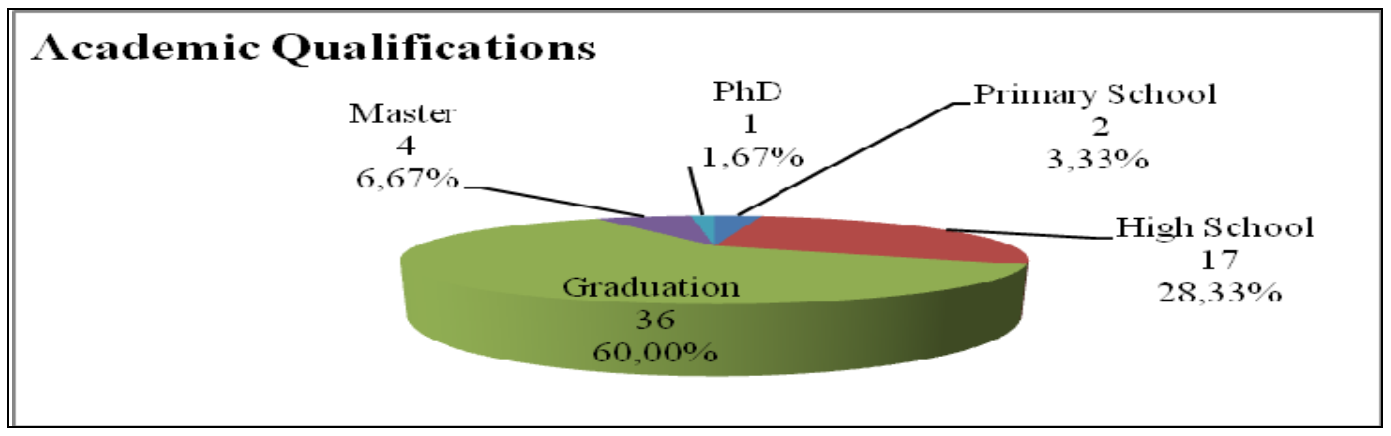

Source: Own (2010)

Crossings can be made of information that seems relevant.

In Figure 6 we can observe that the males there is homogeneity in their distribution by function, while for women there is heterogeneity, with a maximum of 21 surveyed in the role of senior technician, being justified by $60 \%$ of respondents with academic qualifications at the undergraduate level as Chart 5.

\section{Graph 6 - Distribution of sample according to Gender and Job Function}

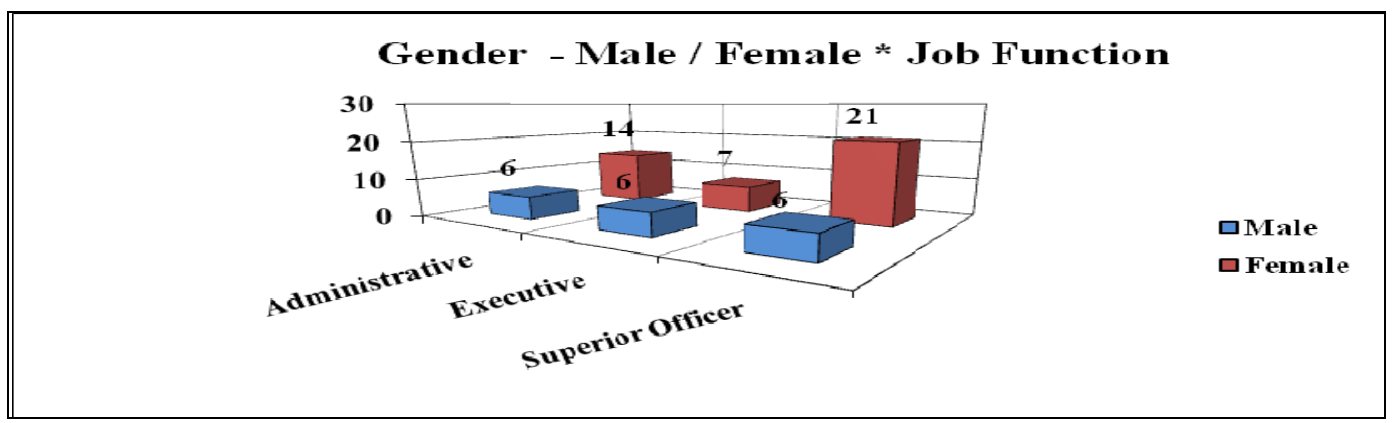

Source: Own (2010) 
In Graph 7 it is observed that the males to female's ages up there, and 9, the highest number of respondents, between 36 and 45 years, while for females the highest number occurs at the age of 46 to 55 .

Graph 7 - Distribution of sample according to the Gender and Age

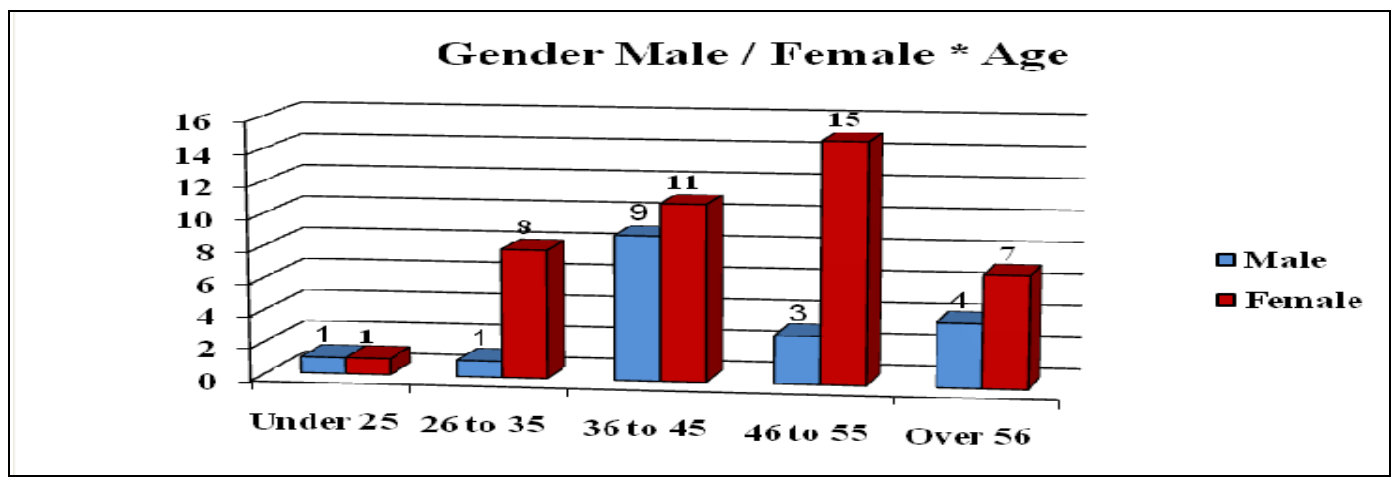

Source: Own (2010)

In Graph 8 we found that older respondents also have more years of service time, a situation perfectly justified and understandable. This is an asset for the study, and, more predictably available data regarding the emotional skills of respondents

Graph 8 - Distribution of sample according to Age and Length of Service

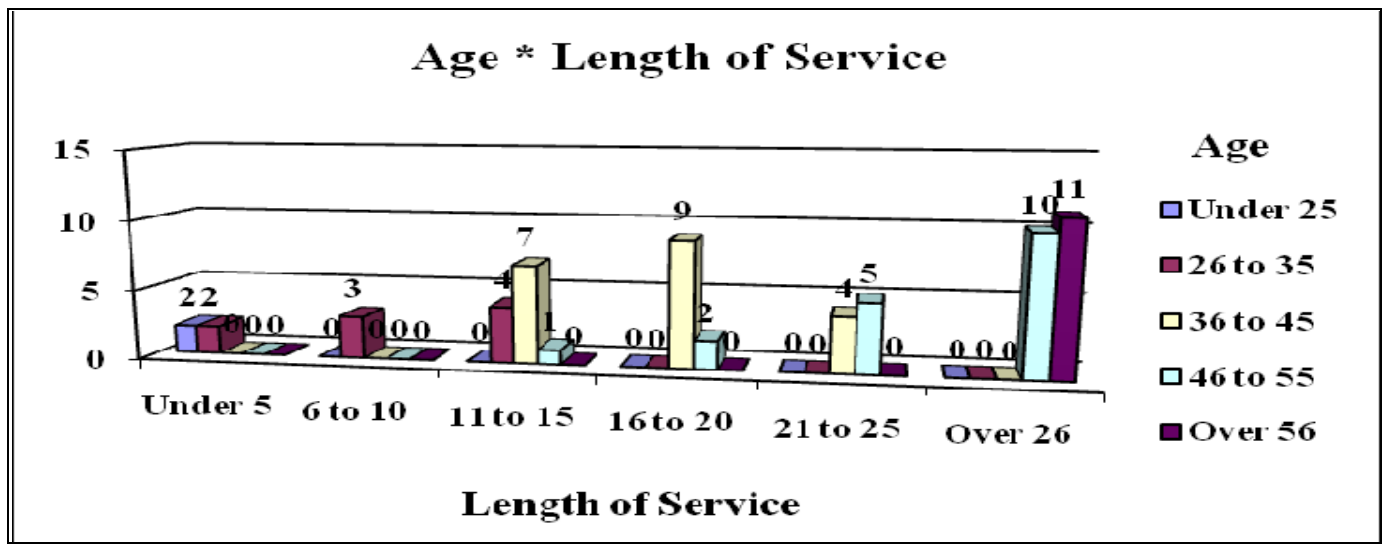

Source: Own (2010)

Graph 9 shows the appreciation of the respondents regarding questions on the factors: emotional experience, you want to hear how they feel their practice emotional, emotional expression, the way in which individuals show their emotions as they speak, how they act or how to make gestures, they integrate here facial expressions, physical sensation, wanting to prove the existence of internal physical sensations of the respondents, physiological manifestations that may not be noticeable to others, triggered by stimuli encountered in the interaction with the environment to the individual ; primitive experience, as the level of conscious experience of emotions but not yet capable of understanding and recognition of 
different emotions and their intensity, empathy is the degree attained when one realizes and intuit the emotions of those around us; interactivity is considered such as the level of understanding of how individuals react to the emotions of each other, ie the interaction between individuals.

As for the 15 items that constitute the group of questions about emotional experience, respondents carried out their assessment. Global analysis of the figures, it appears that, $50.44 \%$ are strongly in agreement and accord, and only $32.67 \%$ in disagreement, we found that respondents are aware of the emotions felt when contact with others, admitting the possibility of control them before the stimuli that trigger them.

For results regarding the factor emotional expression, there is a certain balance in the levels of scale, "agree" and "disagree" and there are respectively $31.11 \%$ and $32.59 \%$. The level "neither agreement nor disagreement" returned $24.26 \%$, reflecting some moderation in emotional expressive attitudes of respondents. Indeed, if we analyze the results as a whole, we can say that the respondents tended not to have feared to externalize their emotions, even if they are visible to others, stressing the possibility of their attitudes to be changed if inaccuracies are verified.

The results obtained for the element enhances physical sensation level was "at odds" with $40 \%$ followed by $28.67 \%$ for "strongly disagree", while others show very low levels. These values can be justified, given that this factor occurs immediately after the stimulus is delivered, i.e. as fractions of seconds, not getting the individual become aware that this will happen.

As regards the primitive experience factor, it is clear the percentage allocated to the level "at odds" of $50.67 \%$, the remaining levels rather distant. Given these values, and identified the issues, it is considered that the respondents claimed to have primary consciousness of their emotions, understanding them and recognizing them.

The empathy factor has values of $47.33 \%$ for the level of "agreement" and to the level "neither agreement nor disagreement" is only 21\%. Data analysis it appears that the respondents, the vast majority, can, with some flexibility to establish stable contacts of empathy with the individuals that constitute the environment.

The interactivity factor shows percentages for the level of "agreement" 47\%, followed by level "neither agreement nor disagreement" 26\%. As a complement to the results, it is stated that the questions were all prepared statements with syntax highlighting positive. Analysis of the data, it appears that respondents have a high predisposition to establish interactions, even if it is necessary behavioral changes occur, to enable positive relationships. 
Graph 9 - Percentage distribution of issues relating to factors Emotional Experience, Expression Emotional, Physical Sensation, Early Experience, Empathy and Interactivity

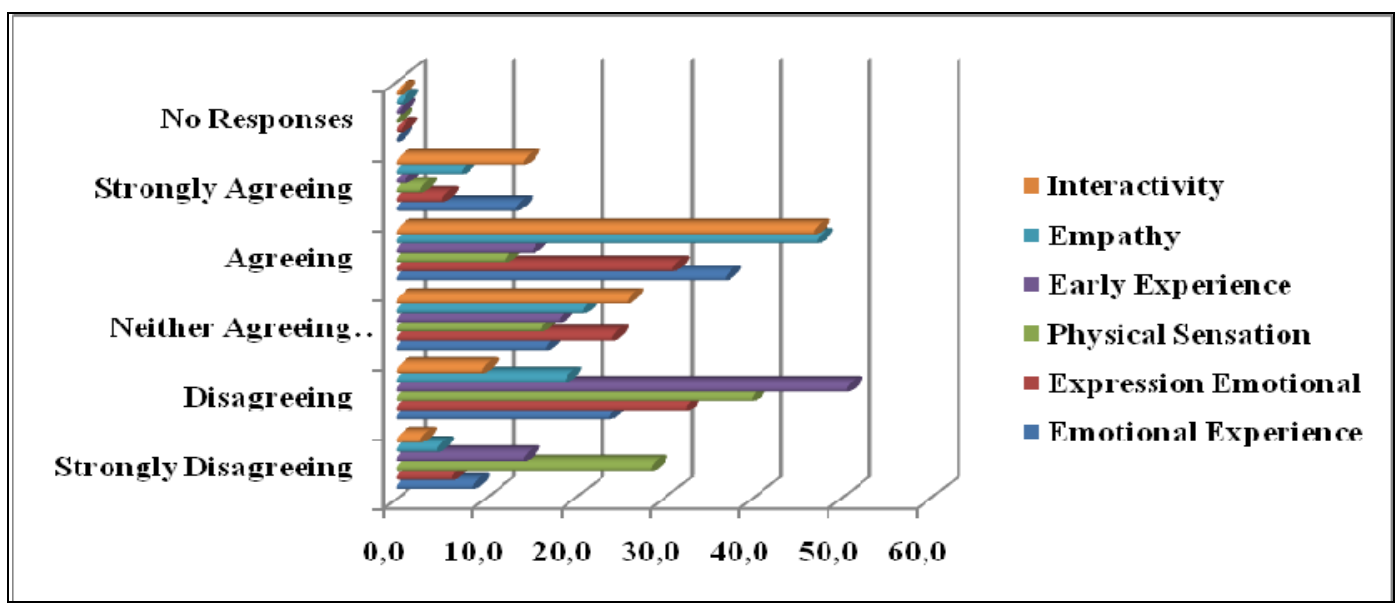

Source: Own (2010)

In an overall assessment can be stated that the selected sample has, overall, a positive emotional awareness, with some emotional abilities, such as the ability to interact, understanding of other emerging ease of empathy, these skills became an asset in environments of rapid change, as the society of today, or even in organizational dynamics.

The strategies that can be seen from the results, partly corroborate the view of Goleman (1997), ranging from, the question remains whether or organize themselves mentally to enable interactivity and perfect empathy, avoiding conflict with others, strengthen their self-esteem, feeling capable of advising others. These facts can be validated with the observation of the results collected, the questions posed to the elements of the sample, as regards the empathy factor and interactivity. The vast majority of respondents is easier in touch with other individuals around them, setting nearby stable and there is a high willingness to interact, even if this interaction arises the need for behavioral adjustments. It is inferred that, with behaviors such positive relationships can only occur in this case, the emotional component of individuals deemed to be balanced, thus presenting emotional intelligence.

The connection found between the recognition of emotional expression and understanding of the causes of emotions is consistent with the view that dimensions are dependent, especially in facial expressions and / or gestures. Therefore, we suggest that the actions of support or management of emotions can promote the development of emotional skills, or individuals who have emotional control capabilities may see their interpersonal relationships improved, and consequently, will present decision-making balanced and pertaining to the situations in which they are involved. Indeed, the results of factor analysis of emotional expression, we can say that the respondents tended not to have fear to externalize their emotions, even though they may be visible to others, stressing the possibility of their attitudes to be changed if it's clear the inaccuracies, this reflection brings us to the concept of emotional learning. 
Thus, and as the object of study, the level of importance of emotional intelligence and emotions in decision making is high it appears the results obtained, it is necessary to be a balance of emotional outbreaks, largely as a result of learning gained over the years. Damásio (2000: 185) states that the experiences acquired throughout life, are classified as pleasant or unpleasant, give rise to a signal of positive or negative nature, through a "marker", and in situations later verified the body uses this mechanism (marker) to make the process of decision making.

It was objective of this research project to study the capabilities of human beings to understand and manage their emotions as well as to conduct of others. In this sense, Goleman (2007: 59) down to two emotional intelligence competencies, personal and social, which are further subdivided into four areas, the first in self-awareness and self-management, and the second in social awareness and relationship management.

With regard to these areas, the results presented in the experience factor indicative of emotional self-awareness and self-management, with $50.44 \%$ of respondents "strongly agreeing" and "agreeing".

At this stage we can answer the question / problem raised in this research.

The decision is a choice, which happens all the time in our lives, and an inevitable consequence of the occurrence of a stimulus or impulse that causes an emotion, that emotion can be managed by the individual, developing various emotional behaviors it is now that the domains of emotional intelligence can be applied as equilibrating elements in interpersonal relationships.

Thus, after the developments made, we are able to address the hypotheses posed.

Hypothesis 1 is confirmed in accordance with the response already given to the issue / problem. Hypothesis 2 was formulated in the negative hypothesis H1, and the H1 hypothesis was confirmed, then the hypothesis $\mathrm{H} 2$ is not confirmed. Hypothesis 3 is confirmed, according to the already presented on the purpose of the study.

Hypothesis 4 is not confirmed, as was the confirmation of $\mathrm{H} 3$.

\section{Final Considerations}

With the identification of concepts and theories through the bibliographic material it was possible to develop tests that led to "satisfactory", and here we present the final conclusions.

After examining the theory, it appears that emotional intelligence and emotions have an important dynamic in regard to the interest that takes on any decision being made by humans, both personally and professionally.

Analysis of the data collected during presentation of the questionnaire was obtained the possible answer to the question raised by the study, "is vital that there is an incentive for there to be a thrill and a consequent decision-making, and emotional intelligence means that one should intervene positively "and is in line with the elements removed from the analysis of literature.

As the overall assessment of the results collected by the questionnaire, we can say that, overall, the constituents of the sample showed a positive emotional awareness, demonstrating 
emotional skills such as self-awareness, self-control, adaptability, the ability to interact the understanding of others giving rise to the ease of empathy of interactivity and conflict management. Thus, these skills are an added value in everyday lives in society, both individually and collectively.

It was recognized that the decision-making measured in interpersonal relations are rooted in emotions triggered by stimuli, and in this process is essential to use the concepts associated with emotional intelligence.

We can even say that since the consequences of emotions stimuli perceived by humans, and delivering of learning pertaining to these emotional balance through the capabilities of emotional intelligence, there is an inevitability of decision making in interpersonal relationships, yet these are positive or negative, depending on the degree of learning occurred. Finally, we note that when performing this work, our proposal is that it may serve to further investigations on this theme, in that it is possible to state the importance of Emotional Intelligence in interpersonal relationships.

\section{References}

BILHIM, João Abreu, (2008). Teoria Organizacional: Estruturas e Pessoas. 6a ed., Lisboa, Instituto Superior de Ciências Sociais e Politicas.

CARMO, Hermano; FERREIRA, Manuela Malheiro, (1998). Metodologia da Investigação Guia para Auto-aprendizagem. Lisboa, Universidade Aberta.

CEITIL, Mário (2009). “High tech, high touch, high value”, Human, nº 4, Abril, 2009, pp. 28.

DAMÁSIO, António, (1999). O Sentimento de Si - O corpo, a Emoção e a Neurobiologia da Consciência. $8^{\mathrm{a}}$ ed.,Lisboa, Publicações Europa América.

DAMÁSIO, António, (2000). O Erro de Descartes - Emoção, Razão e Cérebro Humano. $21^{\text {a }}$ ed.,Lisboa, Publicações Europa América.

DAMÁSIO, António, (2003). Ao Encontro de Espinoza. Lisboa, Publicações Europa América.

EKMAN, Paul, (1992). “Are There Basic Emotions?”, Psychological Review, n³,Vol.99, 1992, pp.550-553. Accessed 24th October 2009 in: http://courses.ed.asu.edu/brem/protected/Library/ekman.pdf.

GIDDENS, Anthony, (2004). Sociologia. 4ª ed., Lisboa, Fundação Calouste Gulbenkien, 725 pp.

GOLEMAN, Daniel, (1997). Inteligência Emocional. n.a.,Temas e Debates.

GOLEMAN, Daniel, (1998). “What Makes a Leader?”, Harvard Business Review, November - December 1998.

GOLEMAN, Daniel, (1999). Trabalhar com Inteligência Emocional. n.a., Circulo de 
Leitores.

GOLEMAN, Daniel, (2000). “Leadership that get results”. Harvard Business Review, 78 [2], 78-90.

GOLEMAN, Daniel, (2005). Emoções que curam - conversas com o Dalai Lama. $5^{\mathrm{a}}$ ed., Rocco-Temas e Debates.

GOLEMAN, Daniel, (2006). Inteligência Social - A Nova Ciência das Relações Humanas. n.a., Círculo de Leitores.

GOLEMAN, Daniel; BOYATZIS, Richard; McKEE, Annie, (2007). Os Novos Lideres - A Inteligência Emocional nas Organizações. $3^{\mathrm{a}}$ ed., Gradiva.

GOLEMAN, Daniel; BENNIS, Warren; O’TOOLE, James, (2009). Transparência - Como os líderes podem criar uma cultura de sinceridade. $1^{\mathrm{a}}$ ed., Gradiva.

LOURENÇO, Luís; ILHARCO, Fernando, (2009). Liderança: As Lições de Mourinho. $8^{\mathrm{a}}$ ed., Lisboa, Prime Books.

PINTO, Amâncio da Costa, (2001). Psicologia Geral. n.a., Lisboa, Universidade Aberta.

ROBBINS, Stephen P., (2008). Fundamentos do Comportamento Organizacional. $7^{\text {a }}$ ed., São Paulo, Prentice Hall.

SEKARAN, Uma, (2003). Research Methods for Business: a Skill Building Approach. 4th edition, New York, John Wiley \& Sons. 